\title{
THE EFFECTS OF ALTERED ARTERIAL TENSIONS OF CARBON DIOXIDE AND OXYGEN ON CEREBRAL BLOOD FLOW AND CEREBRAL OXYGEN CONSUMPTION OF NORMAL YOUNG MEN ${ }^{1}$
}

\author{
By SEYMOUR S. KETY ANd CARL F. SCHMIDT \\ (From the Department of Pharmacology, University of Pennsylvania, Philadelphia)
}

(Received for publication December 4, 1947)

A method for measuring quantitatively the volume of cerebral blood flow in man by inhalation of nitrous oxide (1) found its first application in a study of the cerebral circulatory effects of low $\mathrm{CO}_{2}$ tension achieved by hyperventilation; of high $\mathrm{CO}_{2}$ tension, and of high and low $\mathrm{O}_{2}$ tensions obtained by inhalation of appropriate gas mixtures (2). Only the first part of this study, the effects of active and passive hyperventilation, has been published in detail (3). The purpose of the present paper is to present the remainder of these findings and to derive from them, together with those of the hyperventilation experiments, evidence bearing on the intrinsic control of the human cerebral circulation as revealed by quantitative measurements.

\section{METHODS}

The nitrous oxide technique is described in a preceding report (4). The subjects were young male volunteers in apparently good health. A set of control observations were made after the fasting subject had rested supine for more than an hour. After the control period, the experimental gas mixture (free of nitrous oxide) was administered for 15 to 30 minutes in order to approximate a steady state, and for the removal of $\mathrm{N}_{2} \mathrm{O}$ absorbed by the brain during the control cerebral blood flow determination. At the end of this time a change was quickly made to a gas mixture similar to the preceding one but containing $15 \% \mathrm{~N}_{2} \mathrm{O}$ and a second or "experimental" series of observations was made. The composition of the gas mixtures used was as follows: (1) for hyperventilation, room air followed by $21 \% \mathrm{O}_{2}, 64 \% \mathrm{~N}_{2}, 15 \% \mathrm{~N}_{2} \mathrm{O}$; (2) for increased $\mathrm{CO}_{2}, 5$ or $7 \% \mathrm{CO}_{2}, 21 \% \mathrm{O}_{2}, 74$ or $72 \% \mathrm{~N}_{2}$ followed by 5 or $7 \% \mathrm{CO}_{2}, 21 \% \mathrm{O}_{2}, 59$ or $57 \% \mathrm{~N}_{2}$, $15 \% \mathrm{~N}_{2} \mathrm{O}$; (3) for high $\mathrm{O}_{2}, 100 \% \mathrm{O}_{2}$ followed by $85 \%$ $\mathrm{O}_{2}, 15 \% \mathrm{~N}_{2} \mathrm{O}$; (4) for low $\mathrm{O}_{2}, 10 \% \mathrm{O}_{2}, 90 \% \mathrm{~N}_{2}$ followed by $10 \% \mathrm{O}_{2}, 75 \% \quad \mathrm{~N}_{2}, 15 \% \quad \mathrm{~N}_{2} \mathrm{O}$.

Blood $\mathrm{O}_{2}$ and $\mathrm{CO}_{2}$ analyses were made by the manometric technique of Van Slyke and Neill (5). Blood

\footnotetext{
1 The expenses of these investigations were defrayed by grants from the Office of Scientific Research and Development and the Committee on Research in Dementia Precox, founded by the Supreme Council, $33^{\circ}$ Scottish Rite, Northern Masonic Jurisdiction, U. S. A.
}

$\mathrm{pH}$ measurements were made anaerobically at $37^{\circ} \mathrm{C}$. using a glass electrode. $\mathrm{CO}_{2}$ tension was calculated by means of the nomograms of Peters and Van Slyke (5). Mean arterial blood pressure was obtained directly from the femoral artery by means of a damped mercury manometer; systolic and diastolic pressures were also measured by the usual auscultatory method. In the middle of both the control and experimental periods ballistocardiograms were recorded. These were used for calculation of a value for cardiac output from the formula of Starr and associates (6), using the correction factor of 1.18 found by Cournand, Ranges and Riley (7).

Cerebral oxygen consumption $\left(\mathrm{CMR}_{\mathrm{O}_{2}}\right)$ and cerebrovascular resistance (CVR) were calculated from the cerebral blood flow as described previously (4).

\section{RESULTS}

The essential data obtained are presented in Tables I, II and III. Mean values obtained with active or passive hyperventilation and previously reported (3) are included for the sake of completeness, with a correction in the cerebral blood flow and oxygen consumption values for the more accurate determination of the brain : blood partition coefficient of $\mathrm{N}_{2} \mathrm{O}$ (1.0 instead of the previously used value of 1.3). The arterial and internal jugular $\mathrm{N}_{2} \mathrm{O}$ concentration curves from which the cerebral blood flow is calculated are omitted for the sake of brevity but typical curves are shown in Figure 1.

\section{Effects of $\mathrm{CO}_{2}$ inhalation (5-7\%)}

There were six studies with $5 \% \mathrm{CO}_{2}$ and two with $7 \% \mathrm{CO}_{2}$; these were grouped together for calculation of mean values. Arterial blood $\mathrm{CO}_{2}$ content, $\mathrm{CO}_{2}$ tension, and hydrogen ion concentration all rose as expected. Cerebral blood flow underwent a striking and consistent increase averaging $75 \%$ (from a mean control value of 53 to a mean value of $93 \mathrm{cc} . / 100 \mathrm{~g} . / \mathrm{min}$.). Cerebral oxygen consumption was not significantly changed with the result that the increased volume flow was 
associated with an equivalent decrease in the arteriovenous oxygen difference. Along with the increased cerebral blood flow there was a marked reduction in the mean cerebrovascular resistance from 1.6 to 1.1 resistance units. With respect to the general circulatory effects of $\mathrm{CO}_{2}$, there was a significant rise in arterial blood pressure though cardiac output was not significantly altered. This speaks for a net peripheral vasoconstriction, an effect quite opposite to that exerted on the cerebral circulation.

\section{Effects of high oxygen concentrations}

Inhalation of the high oxygen mixtures (85$100 \%$ ) produced a slight but significant increase in arterial oxygen content with no change in the $\mathrm{CO}_{2}$ content and tension or the $\mathrm{pH}$ of arterial blood. This speaks against any appreciable effects of these oxygen tensions on pulmonary ventilation at least during the first 30 minutes of inhalation. There was a significant decrease of $13 \%$ in mean cerebral blood flow (from 52 to $45 \mathrm{cc} . / 100 \mathrm{~g} . / \mathrm{min}$.) with no change in cerebral oxygen consumption. Cerebrovascular resistance exhibited a moderate increase (from 1.7 to 2.2 resistance units) indicating vasoconstriction in the brain as the probable mechanism for the reduction in cerebral blood flow. There was a significant increase in systolic and diastolic blood pressure on auscultatory measurement and in mean arterial pressure measured di-

TABLE I

Effects of altered arterial $\mathrm{CO}_{2}$ and $\mathrm{O}_{2}$ tensions on blood constituents

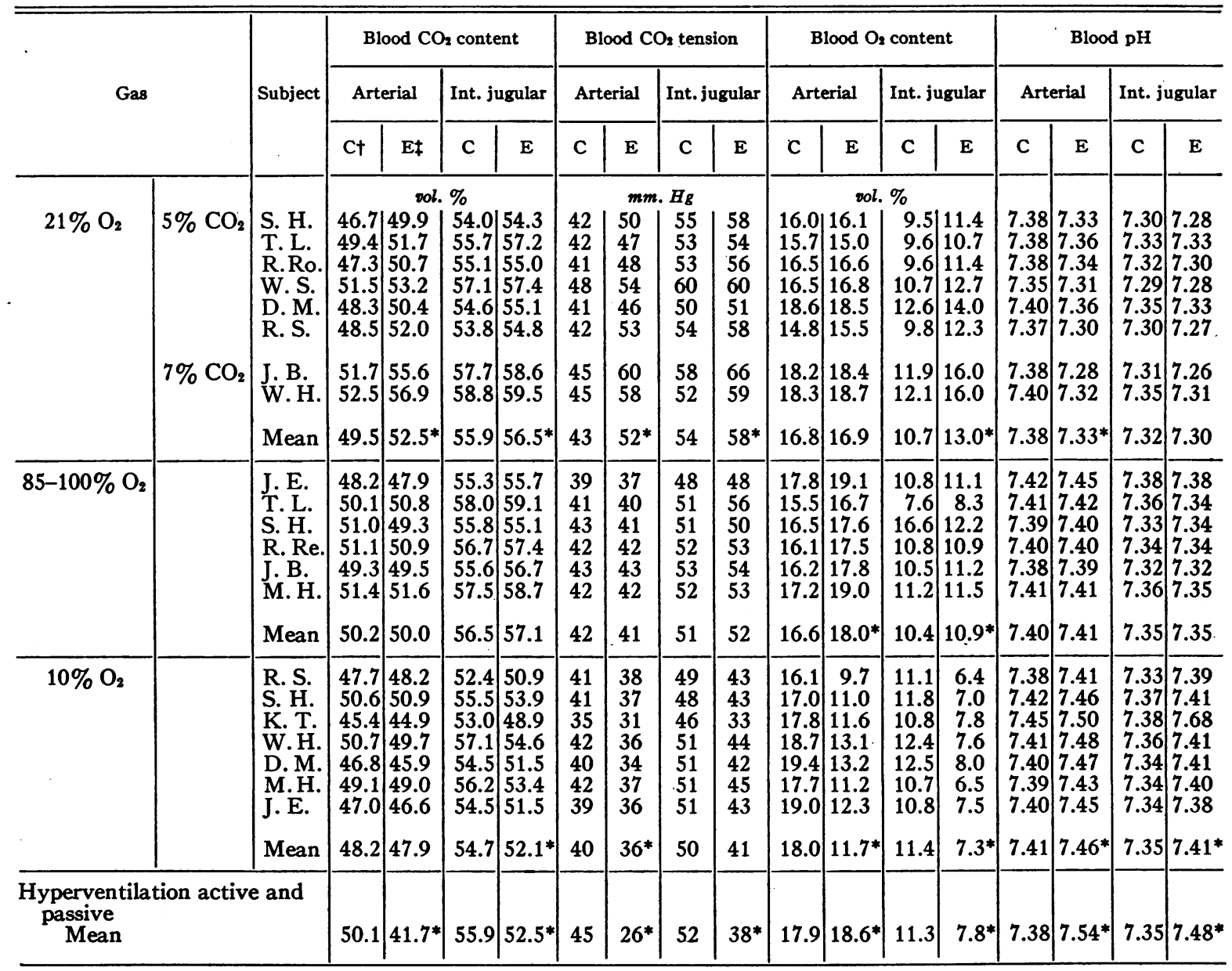

* Indicates statistically significant changes.

$\dagger \mathrm{C}=$ Control period, room air tensions of $\mathrm{O}_{2}$ and $\mathrm{CO}_{2}$.

$\ddagger \mathrm{E}=$ Experimental period, special gas mixture. 
TABLE II

Effects of altered arterial $\mathrm{CO}_{2}$ and $\mathrm{O}_{2}$ tensions on cerebral circulation and metabolism

\begin{tabular}{|c|c|c|c|c|c|c|c|c|c|c|c|c|}
\hline \multirow{3}{*}{\multicolumn{2}{|c|}{ Inspired gas }} & \multirow{3}{*}{ Subject } & \multicolumn{10}{|c|}{ Cerebral } \\
\hline & & & \multicolumn{2}{|c|}{ Blood flow } & \multicolumn{2}{|c|}{$\mathrm{O}_{2}$ consumption } & \multicolumn{2}{|c|}{$\begin{array}{l}\text { Vascular } \\
\text { resistance }\end{array}$} & \multicolumn{2}{|c|}{$\mathbf{R Q}$} & \multicolumn{2}{|c|}{$\mathrm{A}-\mathrm{VO}_{2}$} \\
\hline & & & $\mathrm{C} \dagger$ & $\mathrm{E} \ddagger$ & $\mathrm{C}$ & $\mathrm{E}$ & $\mathrm{C}$ & $\mathrm{E}$ & $\mathrm{C}$ & $\mathrm{E}$ & C & $\mathrm{E}$ \\
\hline \multirow{4}{*}{$21 \% \mathrm{O}_{2}$} & \multirow[b]{2}{*}{$5 \% \mathrm{CO}_{2}$} & & \multicolumn{2}{|c|}{$c c . / 100 \mathrm{~g} . / \mathrm{min}}$. & \multicolumn{2}{|c|}{ cc. $/ 100 \mathrm{~g} . / \mathrm{min}}$. & \multicolumn{2}{|c|}{$\frac{m m \cdot H g}{c c . / 100 \mathrm{~g} \cdot / \mathrm{min} .}$} & \multirow[b]{2}{*}{$\begin{array}{r}1.12 \\
1.03 \\
1.13 \\
.97 \\
1.05 \\
1.06\end{array}$} & \multirow[b]{2}{*}{$\begin{array}{r}.94 \\
1.28 \\
.83 \\
1.02 \\
1.05 \\
1.00\end{array}$} & \multicolumn{2}{|c|}{ vol. \% } \\
\hline & & $\begin{array}{l}\text { S. H. } \\
\text { T. L. } \\
\text { R. Ro. } \\
\text { W. S. } \\
\text { D. M. } \\
\text { R. S. }\end{array}$ & $\begin{array}{l}48 \\
50 \\
46 \\
63 \\
56 \\
63\end{array}$ & $\begin{array}{r}65 \\
67 \\
75 \\
90 \\
80 \\
141\end{array}$ & $\begin{array}{l}3.1 \\
3.1 \\
3.2 \\
3.7 \\
3.4 \\
3.2\end{array}$ & $\begin{array}{l}3.1 \\
2.9 \\
3.9 \\
3.7 \\
3.6 \\
3.9\end{array}$ & $\begin{array}{l}1.7 \\
1.6 \\
1.8 \\
1.3 \\
1.4 \\
1.3\end{array}$ & $\begin{array}{l}1.4 \\
1.3 \\
1.2 \\
0.9 \\
1.2 \\
0.7\end{array}$ & & & $\begin{array}{l}6.5 \\
6.1 \\
6.9 \\
5.8 \\
6.0 \\
5.0\end{array}$ & $\begin{array}{l}4.7 \\
4.3 \\
5.2 \\
4.1 \\
4.5 \\
2.8\end{array}$ \\
\hline & $7 \% \mathrm{CO}_{2}$ & $\begin{array}{l}\mathrm{J} . \\
\mathrm{W} \cdot \dot{\mathrm{H}} .\end{array}$ & $\begin{array}{l}53 \\
45\end{array}$ & $\begin{array}{r}135 \\
90\end{array}$ & $\begin{array}{l}3.3 \\
2.8\end{array}$ & $\begin{array}{l}3.2 \\
2.4\end{array}$ & $\begin{array}{l}1.7 \\
1.9\end{array}$ & $\begin{array}{l}0.8 \\
1.0\end{array}$ & $\begin{array}{r}.95 \\
1.01\end{array}$ & $\begin{array}{l}1.25 \\
1.00\end{array}$ & $\begin{array}{l}6.3 \\
6.2\end{array}$ & $\begin{array}{l}2.4 \\
2.7\end{array}$ \\
\hline & & Mean & 53 & $93^{*}$ & 3.2 & 3.3 & 1.6 & $1.1^{*}$ & 1.04 & 1.05 & 6.1 & $3.8^{*}$ \\
\hline \multirow[t]{2}{*}{$85-100 \% \mathrm{O}_{2}$} & & $\begin{array}{l}\text { J. E. } \\
\text { T. L. } \\
\text { S. H. } \\
\text { R. Re. } \\
\text { J. B. } \\
\text { M. H. }\end{array}$ & $\begin{array}{l}40 \\
50 \\
60 \\
61 \\
57 \\
43\end{array}$ & $\begin{array}{l}34 \\
52 \\
49 \\
55 \\
41 \\
39\end{array}$ & $\begin{array}{l}2.8 \\
4.0 \\
2.9 \\
3.2 \\
3.2 \\
2.6\end{array}$ & $\begin{array}{l}2.7 \\
4.4 \\
2.6 \\
3.7 \\
2.7 \\
2.9\end{array}$ & $\begin{array}{l}2.2 \\
1.8 \\
1.4 \\
1.5 \\
1.5 \\
2.0\end{array}$ & $\begin{array}{l}2.7 \\
1.9 \\
1.8 \\
2.1 \\
2.3 \\
2.5\end{array}$ & $\begin{array}{r}1.01 \\
1.00 \\
.98 \\
.96 \\
1.10 \\
1.02\end{array}$ & $\begin{array}{r}.98 \\
.99 \\
1.07 \\
.98 \\
1.09 \\
.95\end{array}$ & $\begin{array}{l}7.0 \\
7.9 \\
4.9 \\
5.3 \\
5.7 \\
6.0\end{array}$ & $\begin{array}{l}8.0 \\
8.4 \\
5.4 \\
6.7 \\
6.6 \\
7.5\end{array}$ \\
\hline & & Mean & 52 & $45^{*}$ & 3.1 & 3.2 & 1.7 & $2.2^{*}$ & 1.01 & 1.01 & 6.1 & $7.1^{*}$ \\
\hline \multirow[t]{2}{*}{$10 \% \mathrm{O}_{2}$} & & $\begin{array}{l}\text { R. S. } \\
\text { S. H. } \\
\text { K. T. } \\
\text { W. H. } \\
\text { D. M. } \\
\text { M. H. } \\
\text { J. E. }\end{array}$ & $\begin{array}{l}71 \\
60 \\
44 \\
47 \\
57 \\
52 \\
44\end{array}$ & $\begin{array}{l}93 \\
81 \\
82 \\
58 \\
67 \\
75 \\
54\end{array}$ & $\begin{array}{l}3.6 \\
3.1 \\
3.1 \\
3.0 \\
3.9 \\
3.6 \\
3.6\end{array}$ & $\begin{array}{l}3.1 \\
3.2 \\
3.1 \\
3.2 \\
3.5 \\
3.5 \\
2.6\end{array}$ & $\begin{array}{l}1.2 \\
1.2 \\
2.0 \\
1.9 \\
1.5 \\
1.8 \\
2.1\end{array}$ & $\begin{array}{l}0.9 \\
0.8 \\
1.0 \\
1.2 \\
1.2 \\
1.0 \\
1.6\end{array}$ & $\begin{array}{r}.94 \\
.96 \\
1.08 \\
1.01 \\
1.11 \\
1.01 \\
.92\end{array}$ & $\begin{array}{r}.82 \\
.75 \\
1.05 \\
.90 \\
1.08 \\
.94 \\
1.02\end{array}$ & $\begin{array}{l}5.0 \\
5.2 \\
7.0 \\
6.3 \\
6.9 \\
7.0 \\
8.2\end{array}$ & $\begin{array}{l}3.3 \\
4.0 \\
3.8 \\
5.5 \\
5.2 \\
4.7 \\
4.8\end{array}$ \\
\hline & & Mean & 54 & $73^{*}$ & 3.4 & 3.2 & 1.7 & $1.1^{*}$ & 1.00 & .94 & 6.6 & $4.5^{*}$ \\
\hline \multicolumn{3}{|c|}{$\begin{array}{l}\text { Hyperventilation active and } \\
\text { passive } \\
\text { Mean }\end{array}$} & 52 & $34^{*}$ & 3.5 & 3.7 & 1.7 & $2.9^{*}$ & 0.88 & 1.00 & 6.6 & $10.8^{*}$ \\
\hline
\end{tabular}

* Indicates statistically significant changes.

$\dagger \mathrm{C}=$ Control period, room air tensions of $\mathrm{O}_{2}$ and $\mathrm{CO}_{2}$.

$\ddagger \mathrm{E}=$ Experimental period, special gas mixture.

rectly, but there were no observable changes in cardiac rate, stroke volume, or minute output. Here also there must have been vasoconstriction accompanying the inhalation of these concentrations of oxygen, but in this case the cerebral vessels participated.

\section{Effects of $10 \%$ oxygen}

The relative anoxia produced by inhalation of $10 \%$ oxygen was reflected in a pronounced fall in arterial oxygen content from a control value of 18.0 to 11.7 vol. $\%$. Although there were no measurements of pulmonary ventilation an increase in this function must certainly have oc- curred to account for the observed significant decreases in $\mathrm{pCO}_{2}$ and hydrogen ion concentration found in arterial blood. Cerebral blood flow was regularly increased, the average rising from 54 to $73 \mathrm{cc} . / 100 \mathrm{~g} . / \mathrm{min}$., an increase of $35 \%$, which occurred in the face of a significant reduction in femoral mean arterial pressure. There was a decrease in cerebrovascular resistance from 1.7 to 1.1 , showing that anoxia of this degree was just as effective as $5-7 \% \mathrm{CO}_{2}$ in dilating cerebral vessels even though cerebral blood flow was considerably more augmented in the latter case because of the contributing effects on the systemic circulation. There was no consistent or significant change in 


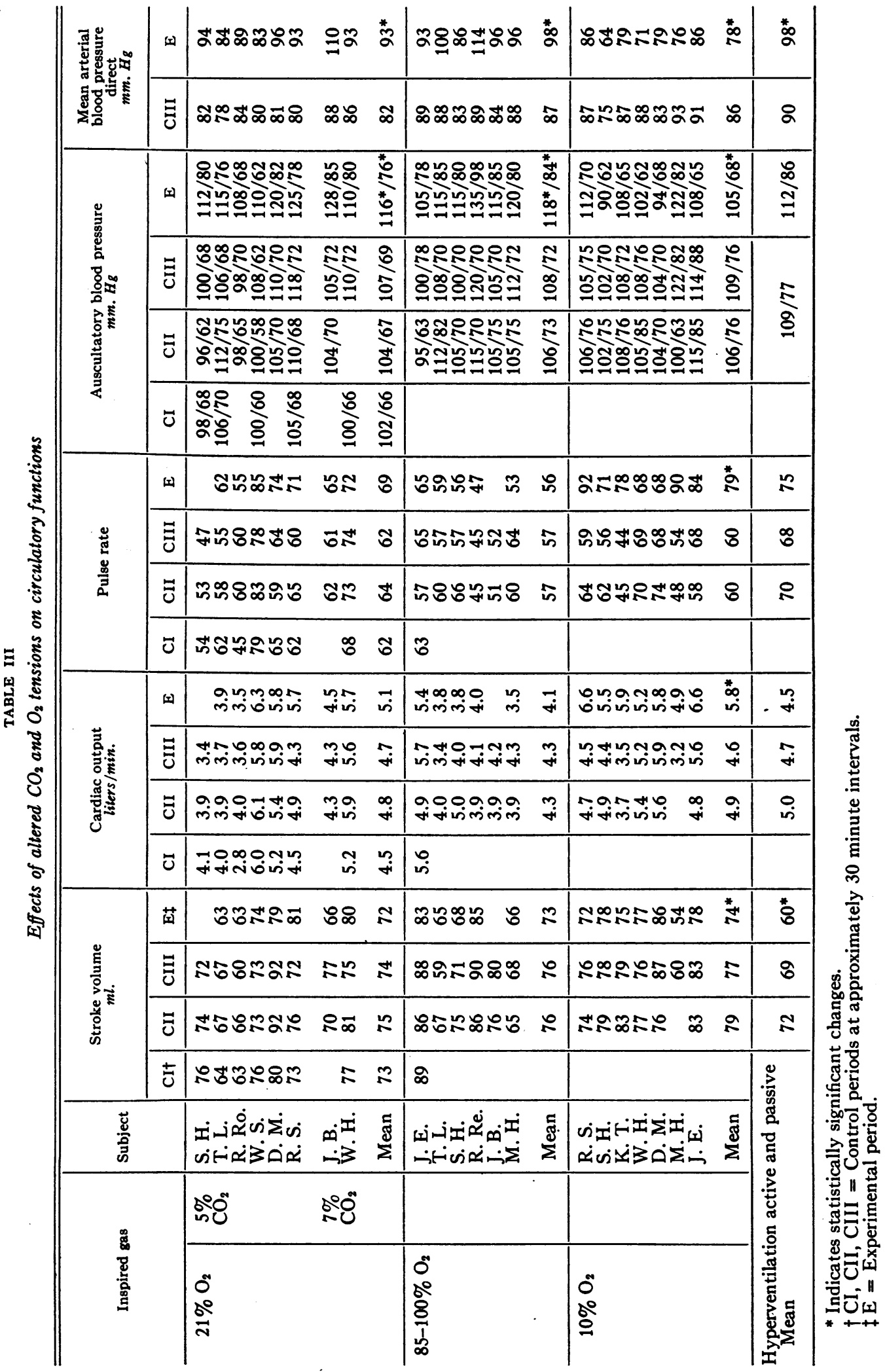



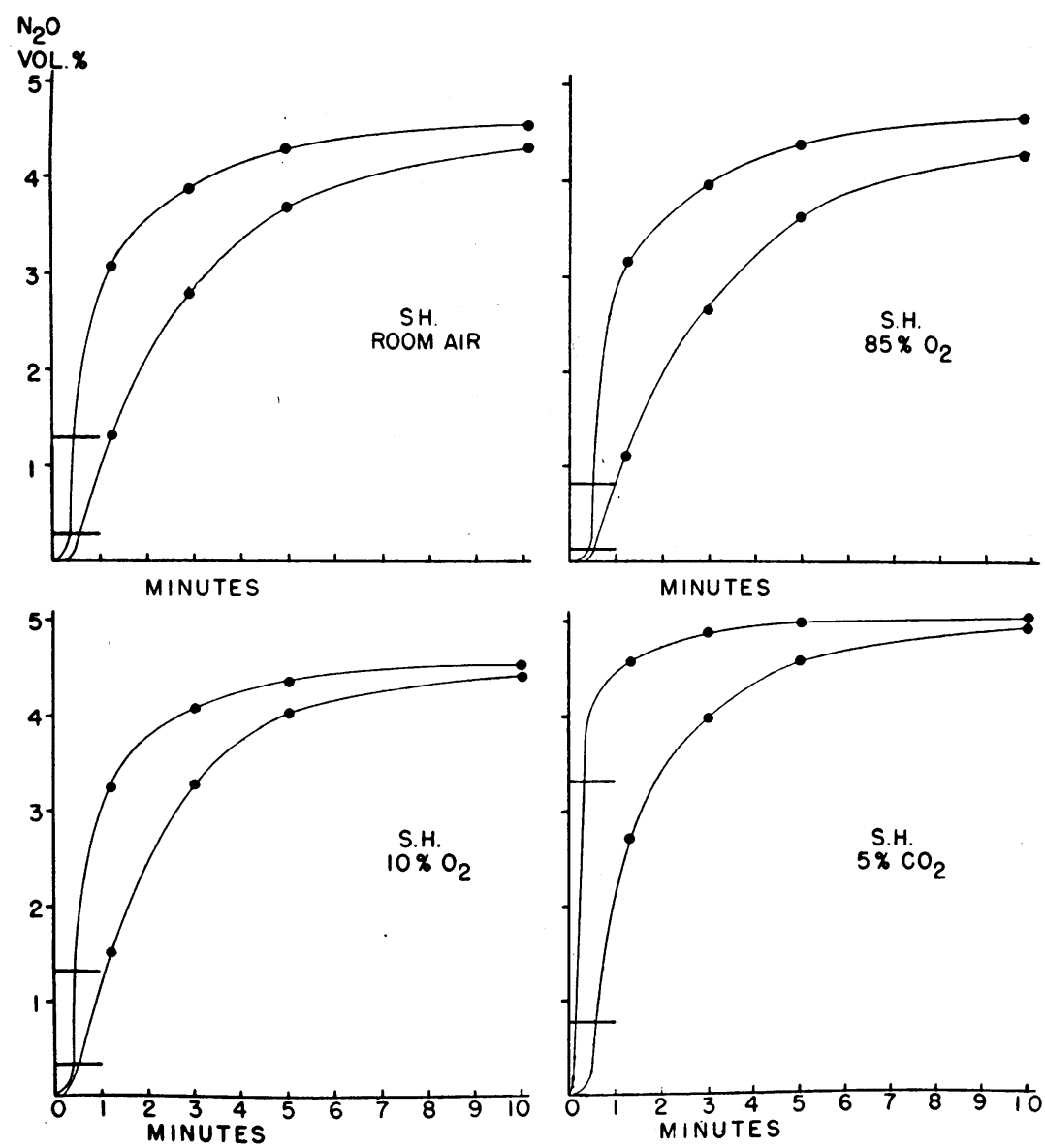

Fig. 1. Sample $\mathrm{N}_{2} \mathrm{O}$ Curves Obtained on One Subject at Different Times Representing One of the Room Air Control Periods, $85 \% \mathrm{O}_{2}, 10 \%$ $\mathrm{O}_{2}$ AND $5 \% \mathrm{CO}_{2}$

cerebral oxygen consumption. The general circulatory effects of anoxia in this group were a significant increase in cardiac output resulting from an acceleration in ventricular rate, yet a fall in mean arterial blood pressure, suggesting a considerable degree of peripheral vasodilatation.

\section{DISCUSSION}

These experimental findings lend the support of quantitative measurements in man to the already prevalent belief ( 8 to 11 ) that the cerebral blood vessels are strongly influenced by the carbon dioxide and oxygen tensions of the arterial blood. They also afford a previously unavailable insight into some important relationships here involved, for the reason that they permit quantitative comparisons in the normal, intact state. Previous observations in unanesthetized man were made by methods which did not justify quantitative deductions $(9,10,12)$ and the only truly quantitative measurements in animals were made under conditions more or less remote from the normal (13).

It is of interest to compare these results on cerebral blood flow with studies on the coronary circulation, the most recent being those on the heart in situ of Eckenhoff, Hafkenschiel and Landmesser (14) who found a reduction of $11 \%$ with pure oxygen, a $64 \%$ increase with $10 \%$ oxygen, but little effect from inhalation of $5-7 \%$ carbon dioxide.

The data on cerebral oxygen consumption demonstrate that except for an increase associated only with active hyperventilation (3) there is no significant change in oxygen utilization by the brain in the ranges of gas tension studied. This lends substance to the assumption made by investigators 
who used the cerebral arteriovenous oxygen difference as a measure of blood flow under similar circumstances (9), although it is difficult to see a justification for such an assumption $a$ priori. Indeed, it is somewhat surprising that neither hyperventilation nor anoxia showed any depression of cerebral oxygen utilization, even though both were accompanied by definite mental changes. These were the only cases, however, which exhibited any decrease in internal jugular oxygen content and this was markedly reduced in both (7.3 and 7.8 vol. $\%$ for $10 \% \mathrm{O}_{2}$ and hyperventilation, respectively). The possibility presents itself that a reduced mean cortical $\mathrm{pO}_{2}$, as reflected in the lower- ing of the $\mathrm{pO}_{2}$ of internal jugular blood, might well be a factor in producing the mental effects. Thus derangements in consciousness may occur when the complex oxidation processes with which consciousness is associated are forced to operate at a lowered oxygen tension even though the gross oxygen consumption by the whole brain may be within normal limits. The conclusion is apparent that the higher psychic functions are associated with biochemical changes so subtle and complex as to render any attempt to describe them in terms of mere oxygen utilization no more adequate than to predict the fidelity of a radio by its power requirements. This is not to imply the con-

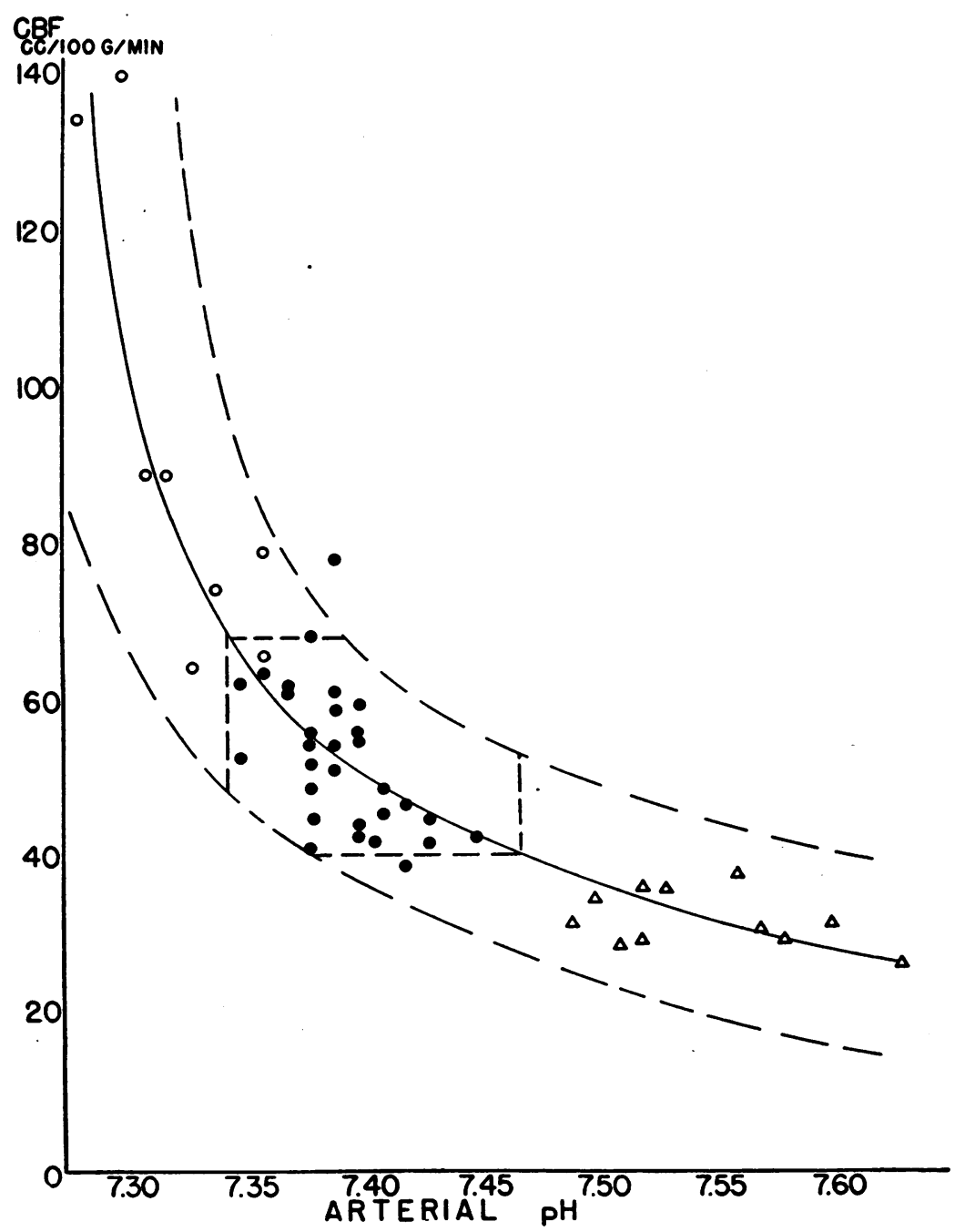

Fig. 2. The Relationship between Cerebral Blood Flow and Arterial pH

The latter was varied from the normal (dots) by hyperventilation (triangles) or by inhalation of $5-7 \% \mathrm{CO}_{2}$ (open circles). The broken curves bound $98 \%$ of the observations while the central polygon encloses $94 \%$ of the normal values. 


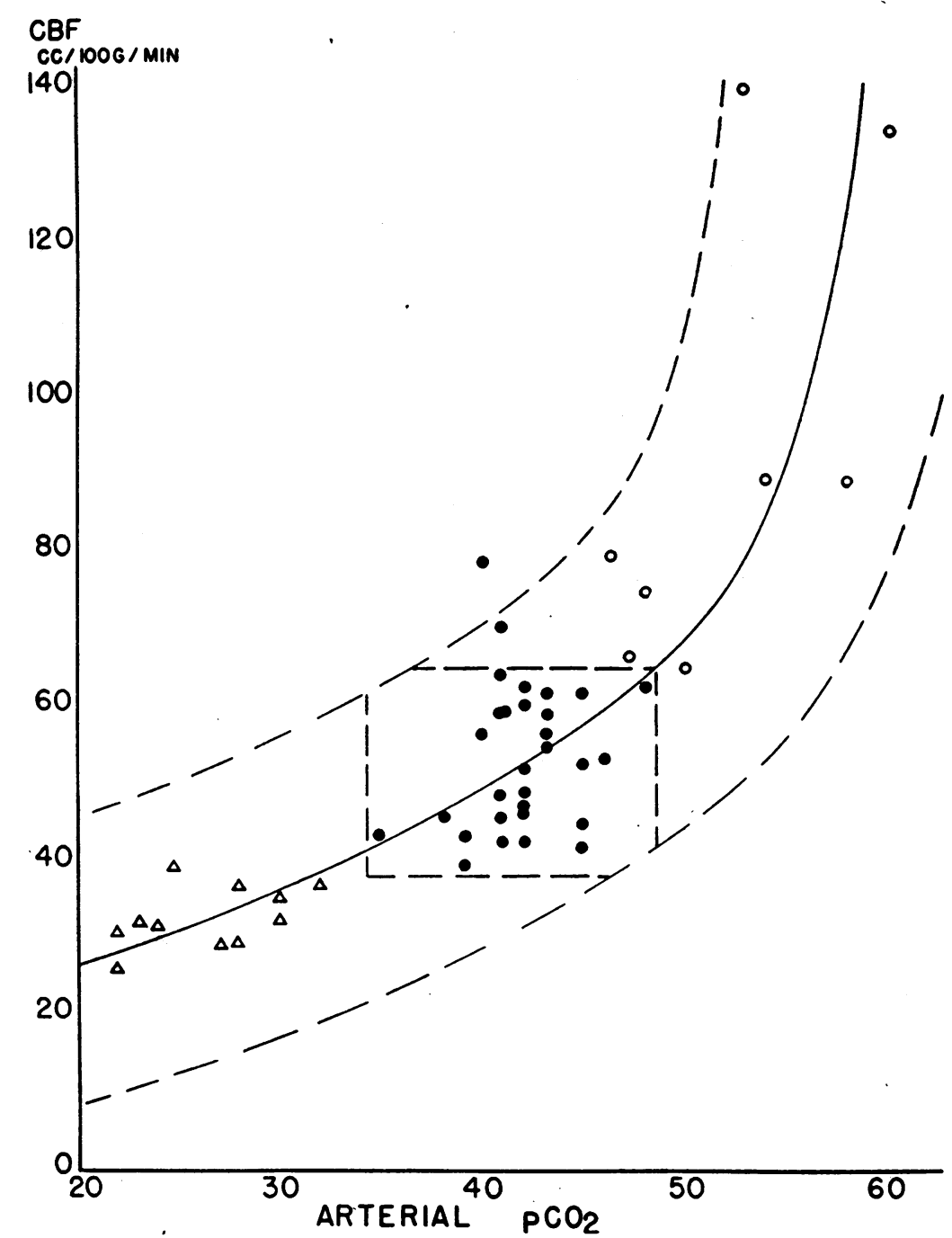

Fig. 3. The Relationship between Cerebral Blood Flow and Arterial $\mathrm{CO}_{2}$ TeNsion

Symbols and construction are similar to those in Figure 2.

verse, that a change in cerebral oxygen utilization does not effect consciousness, for when the former is significantly diminished, mental function deteriorates (15 to 17 ).

Thesse data offer evidence in man for a delicate control over the internal environment of the brain achieved through the intrinsic regulation of the tone of cerebral vessels. Such a homeostatic mechanism has previously been suggested $(11,18$ to 20). An examination of the blood changes which occurred in these studies (Table I) shows that in each case where an abnormal change has been imposed on the arterial blood the change is considerably damped in the internal jugular blood which represents a closer approximation to the state of affairs in the brain itself. Thus in hyperventilation where arterial $\mathrm{CO}_{2}$ content and tension and $\mathrm{pH}$ were changed by 8.4 vol. $\%, 19 \mathrm{~mm}$., and 0.16 units, respectively, the corresponding changes in internal jugular blood were 3.4 vol. $\%, 14 \mathrm{~mm}$, and 0.13 units. The inhalation of $5-7 \% \mathrm{CO}_{2}$ produced changes in arterial $\mathrm{CO}_{2}$ content and tension and $\mathrm{pH}$ of 3.0 vol. $\%, 9 \mathrm{~mm}$., and 0.05 units while internal jugular blood showed corresponding changes of only 0.6 vol. $\%, 4 \mathrm{~mm}$., and 0.02 units. High oxygen inhalation produced a 1.4 vol. \% increase in arterial oxygen content as contrasted with only a 0.5 vol. \% increase in 
cerebral venous blood. Anoxia produced a reduction in arterial oxygen content of 6.3 vol. \%, but only a 4.1 vol. \% decrease in the venous value. Aside from establishing the intrinsic nature of these responses our data throw no further light on the mechanism which mediates them, whether it be by direct action on the vessel walls or by an intrinsic reflex via the well-established cerebral vasodilator nerves (21). In the cases of $\mathrm{CO}_{2}$ inhalation and hyperventilation it is impossible to decide whether the prime stimulus is $\mathrm{CO}_{2}$ tension or the concomitant change in hydrogen ion concentration. Figures 2 and 3 show that very good correlations exist between cerebral blood flow and either arterial $\mathrm{pCO}_{2}$ or arterial $\mathrm{pH}$. There is evidence in our data on patients in diabetic acidosis (16) where an increase in hydrogen ion concentration is associated with a decrease in $\mathrm{pCO}_{2}$ that beyond certain limits arterial $\mathrm{pH}$ may become the dominant factor in cerebrovascular tone as well as respiration.

In the application of this concept to the adjustment of cerebral blood flow to local metabolic needs, which previous work has shown to exist (20) it is a fortunate fact that increased $\mathrm{pCO}_{2}$ and hydrogen ion concentration as well as a decrease in $\mathrm{pO}_{2}$, all products of metabolism, appear individually capable of producing vasodilatation and therefore of maintaining the adjustment of flow to metabolism in the brain, although it is probable that this adjustment is achieved by a summation of these and many other vasodilator products of metabolism.

\section{SUM MARY}

1. The effects of the inhalation of $5-7 \% \quad \mathrm{CO}_{2}$, $85-100 \% \mathrm{O}_{2}$, and $10 \% \mathrm{O}_{2}$, were studied on the composition of arterial and internal jugular blood; on blood flow, oxygen consumption, and vascular resistance of the brain; on cardiac output and blood pressure.

2. $\mathrm{CO}_{2}$ inhaled in concentrations of $5-7 \%$ produces an increase in cerebral blood flow averaging $75 \% . \quad \mathrm{O}_{2}$ inhaled in concentrations of $85-100 \%$ is associated with a reduction in cerebral blood flow of $13 \%$, while $10 \% \mathrm{O}_{2}$ produced an increase of $35 \%$ in this function. These changes are statistically significant.

3. Calculation of cerebrovascular resistance indicates that in every case the change in blood flow is due to a change in the vascular resistance of the brain.

4. Cerebral oxygen consumption is not significantly altered by changes in the composition of inspired air over the ranges studied.

5. Mean arterial blood pressure rose significantly during the $\mathrm{CO}_{2}$ and high $\mathrm{O}_{2}$ inhalations and fell slightly with $10 \% \mathrm{O}_{2}$.

6. The only significant change in cardiac minute volume was an increase which occurred during $10 \% \mathrm{O}_{2}$ inhalation and resulted from an increase in rate rather than stroke volume.

\section{ACKNOWLEDGMENT}

The authors wish to acknowledge the painstaking assistance of Mr. Walter L. Kester and Mr. Theodore D. Whitsel in the manometric analyses, and the splendid cooperation of our 12 subjects, members of a Civilian Public Service Unit.

\section{BIBLIOGRAPHY}

1. Kety, S. S., and Schmidt, C. F., The determination of cerebral blood flow in man by the use of nitrous oxide in low concentrations. Am. J. Physiol., 1945, 143, 53.

2. Kety, S. S., and Schmidt, C. F., Effects of alterations in the arterial tensions of carbon dioxide and oxygen on cerebral blood flow and cerebral oxygen consumption of normal young men. Federation Proc., 1946, 5, 55.

3. Kety, S. S., and Schmidt, C. F., The effects of active and passive hyperventilation on cerebral blood flow, cerebral oxygen consumption, cardiac output and blood pressure of normal young men. J. Clin. Invest., 1946, 25, 107.

4. Kety, S. S., and Schmidt, C. F., The nitrous oxide method for the quantitative determination of cerebral blood flow in man; theory, procedure and normal values. J. Clin. Invest., 1948, 27, 476.

5. Peters, J. A., and Van Slyke, D. D., Quantitative Clinical Chemistry. Williams and Wilkins, Baltimore, 1931.

6. Starr, I., Rawson, A. J., Schroeder, H. A., and Joseph, N. R., Studies on the estimation of cardiac output in man, and of abnormalities in cardiac function, from the heart's recoil and the blood's impacts: The ballistocardiogram. Am. J. Physiol., 1939, 127, 1.

7. Cournand, A., Ranges, H. A., and Riley, R. L., Comparison of results of the normal ballistocardiogram and a direct Fick method in measuring the cardiac output in man. J. Clin. Invest., 1942, 21, 287.

8. Schmidt, C. F., The influence of cerebral blood-flow on respiration. I. The respiratory responses to changes in cerebral blood-flow. Am. J. Physiol., 1928, 84, 202. 
9. Lennox, W. G., and Gibbs, E. L., The blood flow in the brain and the leg of man, and the changes induced by alteration of blood gases. J. Clin. Invest., 1932, 11, 1155.

10. Gibbs, F. A., Gibbs, E. L., and Lennox, W. G., Changes in human cerebral blood flow consequent on alterations in blood gases. Am. J. Physiol., 1935, 111, 557.

11. Schmidt, C. F., and Hendrix, J. P., The action of chemical substances on cerebral blood-vessels. A. Research Nerv. \& Ment. Dis., Proc., 1938, 18, 229.

12. Ferris, E. B., Jr., Objective measurement of relative intracranial blood flow in man. Arch. Neurol. \& Psychiat., 1941, 46, 377.

13. Dumke, P. R., and Schmidt, C. F., Quantitative measurements of cerebral blood flow in the macacque monkey. Am. J. Physiol., 1943, 138, 421.

14. Eckenhoff, J. E., Hafkenschiel, J. H., and Landmesser, C. M., The coronary circulation in the dog. Am. J. Physiol., 1947, 148, 582.

15. Kety, S. S., Shenkin, H. A., and Schmidt, C. F., The effects of increased intracranial pressure on cere- bral circulatory functions in man. J. Clin. Invest., 1948, 27, 493.

16. Kety, S. S., Polis, B. D., Nadler, C. S., and Schmidt, C. F., The blood flow and oxygen consumption of the human brain in diabetic acidosis and coma. J. Clin. Invest., 1948, 27, 500.

17. Kety, S. S., Woodford, R. B., Harmel, M. H., Freyhan, F. A., Appel, K. E., and Schmidt, C. F., Cerebral blood flow and metabolism in schizophrenia. The effects of barbiturate semi-narcosis, insulin coma and electroshock. Am. J. Psychiat., 1948, In press.

18. Schmidt, C. F.; and Pierson, J. C., The intrinsic regulation of the blood vessels of the medulla oblongata. Am. J. Physiol., 1934, 108, 241.

19. Gibbs, E. L., Gibbs, F. A., Lennox, W. G., and Nims, L. F., Regulation of cerebral carbon dioxide. Arch. Neurol. \& Psychiat., 1942, 47, 879.

20. Schmidt, C. F., Kety, S. S., and Pennes, H. H., The gaseous metabolism of the brain of the monkey. Am. J. Physiol., 1945, 143, 33.

21. Chorobski, J., and Penfield, W., Cerebral vasodilator nerves and their pathway from the medulla oblongata. Arch. Neurol. \& Psychiat., 1932, 28, 1257. 